\title{
Parabrachial Internal Lateral Neurons Convey Nociceptive Messages from the Deep Laminas of the Dorsal Horn to the Intralaminar Thalamus
}

\author{
Laurence Bourgeais, Lénaïc Monconduit, Luis Villanueva, and Jean-François Bernard \\ Institut National de la Santé et de la Recherche Médicale U-161, F-75014 Paris, France
}

This study investigates the physiological properties of parabrachial internal lateral (PBil) neurons that project to the paracentral thalamic (PC) nucleus using antidromic activation and single-unit recording techniques in anesthetized rat. We reported here that most of these neurons responded exclusively to the nociceptive stimulation of large receptive fields with a sustained firing that often outlasted the stimulus up to several minutes. These responses were depressed by intravenous morphine.

Our results demonstrated a novel spino-PBil-PC pathway, which transmits nociceptive messages to the PC nucleus, which in turn projects to the prefrontal cortex. Recent clinical imaging studies showed the important participation of prefrontal cortex in emotional response to pain. This spino-PBil-PC pathway may explain how nociceptive messages reach the prefrontal cortex and thus trigger unbearable aversive aspects of pain.

Key words: parabrachial area; thalamus; intralaminar nuclei; paracentral nucleus; dorsal horn; nociception
Old clinical reports (Freeman and Watts, 1948), as well as more recent brain imaging studies (Rainville et al., 1997), demonstrated that the prefrontal cortex plays an important role in the processing of aversive component of pain. However, the pathways that carry the nociceptive information to this brain region remain poorly understood. The spinothalamic tract projects primarily to the sensory relay nuclei in the "lateral" thalamus and only moderately to the "medial" thalamic nuclei, which in turn project to the prefrontal regions (Willis et al., 1995). It is generally believed that laminas V/VI of the dorsal horn (a major link of the nociceptive system; Besson and Chaouch, 1987) reach the medial thalamus rather indirectly via spino-reticulo-thalamic pathways. The two main candidates to convey nociceptive messages from the deep spinal laminas to the medial thalamus are the gigantocellular reticular (Gi) nucleus (Casey, 1971; Bowsher, 1976) and the subnucleus reticularis dorsalis (SRD), in the medulla (Villanueva et al., 1996, 1998). Nonetheless, spinal inputs to Gi fit poorly with reticular areas that project to the thalamus (Craig and Dostrovsky, 1999), and SRD neurons project primarily to the ventromedial nucleus (Villanueva et al., 1998; Monconduit et al., 1999) but spare most of the intralaminar thalamus and noticeably the paracentral (PC) nucleus.

Recently, the parabrachial internal lateral nucleus (PBil) has been suggested as a possible nociceptive relay between the deep spinal laminas and a part of the intralaminar thalamus that mainly project to prefrontal compartments (Fig. 1). Indeed, this nucleus receives an extensive input from nociceptive neurons in laminas

Received Oct. 27, 2000; revised Dec. 27, 2000; accepted Jan. 4, 2001.

This work was supported by a grant from the Institut National de la Santé et de la Recherche Médicale and the Institut UPSA de la douleur (Paris, France). We thank Dr. R. Burstein for advice in the preparation of this manuscript, J. Martin for histology, and R. Rambur for photography.

Correspondence should be addressed to Dr. Jean-François Bernard, Institut National de la Santé et de la Recherche Médicale U-161, 2 rue d'Alésia, F-75014 Paris, France. E-mail: jfbernard@broca.inserm.fr.

Copyright (C) 2001 Society for Neuroscience 0270-6474/01/212159-07\$15.00/0
V/VI of the spinal cord (Kitamura et al., 1993; Bernard et al., 1995; Feil and Herbert, 1995); it projects to the PC and to a lesser extent in other intralaminar thalamic nuclei (see also Fulwiler and Saper, 1984; Hermanson and Blomqvist, 1997b; Bester et al., 1999), and noxious stimulation evoked a marked expression of phospho-cAMP response element-binding protein in and around the PBil (Hermanson and Blomqvist, 1997a). In this study, we investigated the physiological properties of PBil neurons that project to the PC nucleus using antidromic stimulation and singleunit recording techniques.

\section{MATERIALS AND METHODS}

Animal preparation. Experiments were performed on 59 Sprague Dawley male rats weighing 250-300 gm. The animals were deeply anesthetized with $2 \%$ halothane in a nitrous oxide/oxygen mixture (2:3-1:3), paralyzed by an intravenous injection of gallamine triethiodide (Flaxedil), and artificially ventilated using a Palmer pump. The expiratory end tidal $\mathrm{CO}_{2}$ and the core temperature were maintained at $\sim 4 \%$ and $37 \pm 0.5^{\circ} \mathrm{C}$, respectively. The heart rate and blood pressure were continuously monitored. The animals were mounted in a stereotaxic frame, the head being fixed in a dorsiflexed position (incisor bar elevated $10 \mathrm{~mm}$ above the standard position) (Paxinos and Watson, 1998). After surgery, the halothane level was reduced to $0.5-0.7 \%$, and the mixture of nitrous oxide/ oxygen was maintained at 2:3-1:3 to achieve the level of anesthesia that was adequate for ethical purposes but did not excessively depress neuronal responses to noxious stimuli (Benoist et al., 1984).

Recordings. Extracellular unit recordings were made with glass micropipettes $(10-15 \mathrm{M} \Omega)$ filled with a mixture of $\mathrm{NaCl}(5 \%)$ and Pontamine sky blue dye (2\%). Single-unit activity and blood pressure were digitized and monitored on-line using a data acquisition system (CED 1401 with Spike 2 software; Cambridge Electronic Design, Cambridge, UK). To record neurons in the PBil, the micropipettes were inserted in the brain by using the following coordinates: $1.0-3.0 \mathrm{~mm}$ rostral to lambda and $1.2-1.7 \mathrm{~mm}$ lateral to the midline. The depth was between 5.5 and $7.5 \mathrm{~mm}$ from the surface.

Stimulation in the PC thalamic region was applied with a linear array of three concentric monopolar electrodes, and the distance between two adjacent center contacts of the array was $600 \mu \mathrm{m}$. The three center contacts (100 $\mu \mathrm{m}$ in diameter; $150 \mu \mathrm{m}$ in length) could be independently stimulated. The array of antidromic stimulating electrode was inserted 

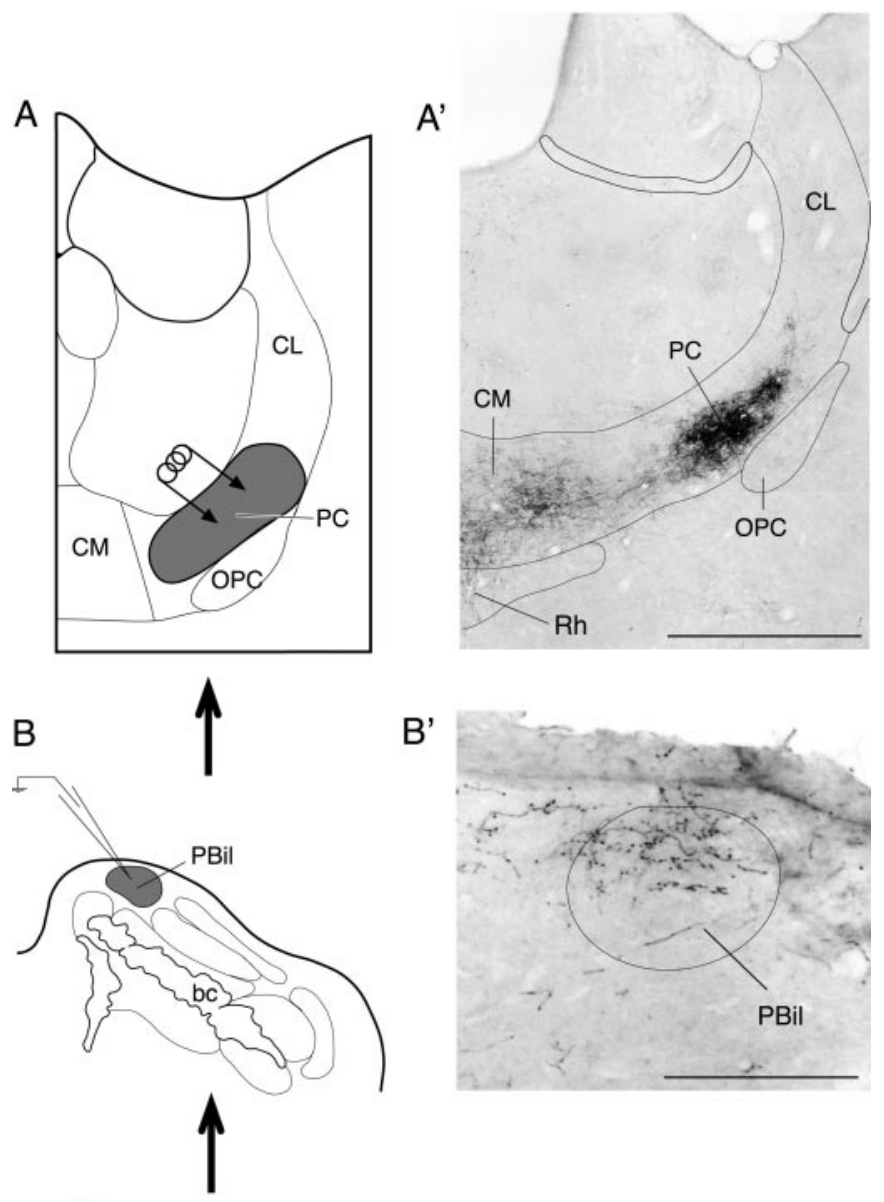

C

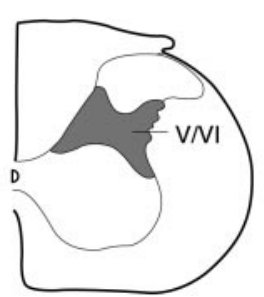

Figure 1. Schematic representation of the experimental design in relation to the spino-PBil-PC nociceptive pathway. $A$, Antidromic stimulation delivered in the PC nucleus (gray). $A^{\prime}$, Terminal labeling in the PC nucleus from Phaseolus vulgaris leucoagglutinin (PHA-L) injection in the PBil (modified from Bester et al., 1999). B, Unitary recording in the PBil nucleus (gray). $B^{\prime}$, Terminal labeling in the PBil nucleus from PHA-L injection in spinal reticular lamina $\mathrm{V}$ (modified from Bernard et al., 1995). $C$, Spinal region ( gray) that projects densely to the PBil. Scale bars: $A^{\prime}, 1$ $\mathrm{mm} ; B^{\prime}, 500 \mu \mathrm{m}$. $C L$, Central lateral thalamic nucleus; $C M$, central medial thalamic nucleus; $O P C$, oval paracentral thalamic nucleus; $R h$, rhomboid thalamic nucleus; V/VI, spinal laminas V/VI.

into the PC thalamic region on the right side of the brain with the following coordinates: $1-1.4 \mathrm{~mm}$ rostral to bregma and $1.5 \mathrm{~mm}$ lateral to the midline, with a depth between 5.5 and $7.5 \mathrm{~mm}$. When a unit was backfired from one depth, the site of minimum threshold was determined by moving the stimulating electrode at different depths. Finally, the electrode was placed to the site of minimum threshold for testing the three main criteria of antidromic activation: (1) the stability of the latency, (2) the ability for the evoked response to follow high-frequency stimulation $(>500 \mathrm{~Hz})$, and (3) the observation of a systematic collision between the evoked antidromic response and one orthodromic spike.

Natural and electrical cutaneous stimulation. Innocuous mechanical (touch, brushing, rubbing, pressure, and stroking) and proprioceptive (movements of joints) stimuli were applied to the limbs, the tail, and the face. Mechanical and thermal noxious stimuli were applied to the paws, the tail, and the face using calibrated forceps, water bath, or water jet. Graded pressures $\left(2-64 \mathrm{~N} / \mathrm{cm}^{2}\right.$; exponential $(\times 2)$ steps; pressure surface of $\left.\sim 0.5 \mathrm{~cm}^{2}\right)$ or temperatures $\left(40-52^{\circ} \mathrm{C} ;+2^{\circ} \mathrm{C}\right.$ steps $)$ applied in a $24 \mathrm{sec}$ period were used to determine the encoding properties of the neurons. A delay of $3 \mathrm{~min}$, at least, was used between successive thermal stimuli of the same part of the receptive field.

Electrical square-wave stimuli (2 msec duration) were delivered through pairs of stainless steel stimulating electrodes inserted subcutaneously into the cheeks, the paws, and the tail. The effects of the repeated application of the electrical stimulus $(30$ per trial, $0.66 \mathrm{~Hz})$ were analyzed with the use of peristimulus histograms (PSTHs).

Histological controls. In most experiments, only one unit per animal was tested. The recording sites of the 113 units antidromically identified or not were each marked by electrophoretic ( $5 \mu \mathrm{A}$ direct current; $30 \mathrm{~min}$ duration; cathode in the micropipette) deposit of Pontamine sky blue at the tip of the micropipette. The location of stimulating electrodes in the thalamus nucleus were marked by iron deposit at the tip of the electrode (10- $\mu \mathrm{A}$ direct current; $30 \mathrm{sec}$ duration; anode connected to the electrode). At the end of the experiment, the brain was removed and fixed in a mixture of $8 \mathrm{vol}$ of $1 \%$ potassium ferricyanide in $10 \%$ formalin solution added to 2 vol of $2 \%$ acetic acid in $95 \%$ alcohol solution for 3-5 d. This procedure induced the formation of Prussian blue staining at the tip of stimulating electrode. The tissue was cut in $100-\mu$ m-thick sections and Nissl-stained. Recording and stimulating sites were determined by microscopic examination and then plotted onto a series of camera lucida drawings.

Data analysis. The magnitude of response was defined as the mean firing frequency during the stimulation minus the ongoing activity before the stimulation. The $t$ test and ANOVA test were used for statistical analysis. Data are generally presented as means \pm SE.

\section{RESULTS}

The results presented below were obtained from 29 PBil neurons that were antidromically activated from the PC nucleus.

The spontaneous activity of the PBil neurons was generally low; most of them (22 of 29) had a low rate of spontaneous activity $(<0.5 \mathrm{~Hz})$. Twenty-one neurons were located within the PBil nucleus, and eight were located within $100 \mu \mathrm{m}$ from its borders (Fig. 2). Sixty-five percent of the PBil neurons were nociceptive, i.e., driven by mechanical and thermal stimuli almost only within noxious ranges, and $35 \%$ of the PBil neurons were unresponsive.

All of the PBil-thalamic neurons fulfilled the criteria for antidromic activation (Fig. 3A-C) (see Materials and Methods). The mean latency was $8.4 \pm 0.8 \mathrm{msec}(n=29$; range of $2.6-20 \mathrm{msec})$ (Fig. $3 F$ ). Such latencies, with an estimated distance of $7 \mathrm{~mm}$ between the parabrachial area and the PC nucleus, indicate a slow conduction velocity in the $0.37-2.8 \mathrm{~m} / \mathrm{sec}$ range. Most lowthreshold points for antidromic activation were located in the PC nucleus or in its close vicinity and in the parafascicular nucleus (Fig. 3D,E).

\section{Response to natural stimulation of PBil nociceptive neurons}

Innocuous thermal (temperature of $\leq 44^{\circ} \mathrm{C}$ ) or mechanical (touch or light brush; pressure of $\leq 4 \mathrm{~N} / \mathrm{cm}^{2}$ ) stimuli were generally ineffective, and the discharges were observed only near the nociceptive threshold (Fig. 4). The application of noxious stimuli (temperature of $>44^{\circ} \mathrm{C}$; pressure of $>4 \mathrm{~N} / \mathrm{cm}^{2}$ ) gave rise to a rapid tonic discharge throughout the stimulation period (Fig. 4) that often $(56 \%)$ lasted many seconds after the termination of the stimulus (Fig. 4A,B2). These marked afterdischarges lasted $74 \pm$ $13 \mathrm{sec}$ after thermal stimuli and $153 \pm 29 \mathrm{sec}$ after mechanical stimuli.

Among the 19 nociceptive neurons, 10 had a large receptive field (the entire body), seven had a medium receptive field (two paws or several regions but not the entire body), and only two had a small receptive field (one part of the body). All receptive fields 

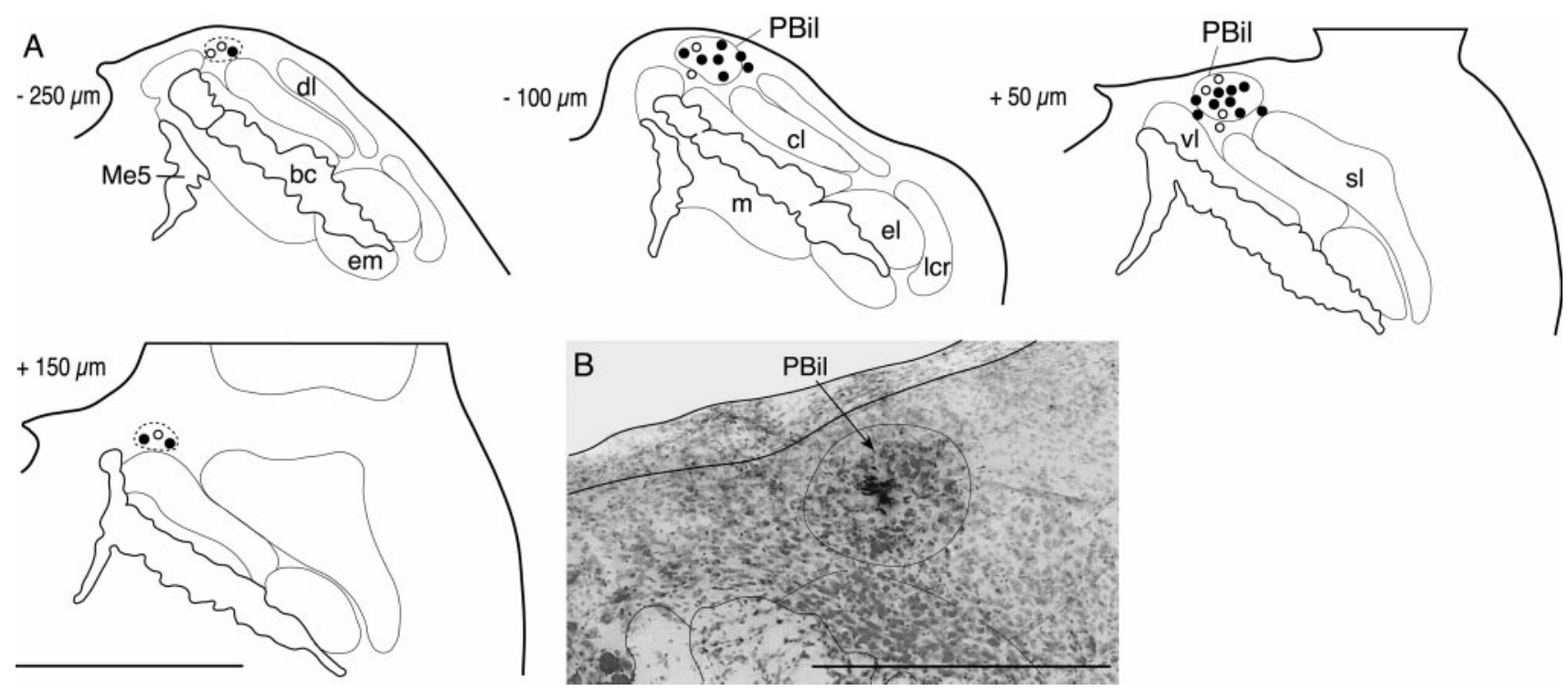

Figure 2. Recording sites of parabrachiothalamic neurons in drawings of coronal sections through the parabrachial area, from caudal to rostral $(A)$. Distance of each level caudal $(-)$ or rostral $(+)$ to the coronal plane in which the inferior colliculus merges with the pons is indicated in micrometers. Open circle, Unresponsive neuron; black circle, nociceptive neuron. $B$, Microphotograph of Pontamine sky blue deposit labeling the recording site in the PBil. Scale bars: $A, B, 1 \mathrm{~mm} . b c$, brachium conjunctivum; $c l$, parabrachial central lateral nucleus; $d l$, parabrachial dorsal lateral nucleus; $e l$, parabrachial external lateral nucleus; em, external medial; lcr, parabrachial lateral crescent area; $m$, medial; $M e 5$, mesencephalic trigeminal nucleus; $s l$, parabrachial superior lateral nucleus; $v l$, parabrachial ventral lateral nucleus.

included a restricted area of the body from which we could obtain a more intense activation, the preferential receptive field (PRF).

\section{Encoding properties of the PBil nociceptive neurons}

The stimulus-response curves of individual neurons are in Figure 5A1-B1. They demonstrated a similar feature: they were monotonic and positive from the threshold to the maximum response, $48^{\circ} \mathrm{C}$ for the thermal stimuli and $16 \mathrm{~N} / \mathrm{cm}^{2}$ for the mechanical. After these points, the curves were clearly decreasing.

The mean thermal thresholds of the PBil neurons was $44.8 \pm$ $0.6^{\circ} \mathrm{C}(n=15)$. The mean thermal curve could be divided in three phases (Fig. 5A2). In the first phase, between 40 and $44^{\circ} \mathrm{C}$, around the threshold, the slope of the curve was positive and increased slowly. In the second phase, from 44 up to $48^{\circ} \mathrm{C}$, the curve increased strongly and the slope was very steep. Then, in the last phase, between 48 and $52^{\circ} \mathrm{C}$, the curve distinctly decreased and the slope became negative. From 42 up to $48^{\circ} \mathrm{C}$, this curve is quite identical to the curve obtained in a previous work, in the external parabrachial area (PBe) (see Discussion). However, after this point, a marked difference appeared; the PBe curve still increased, whereas the PBil curve decreased.

The mean mechanical thresholds of the PBil neurons was $8 \pm$ $2.8 \mathrm{~N} / \mathrm{cm}^{2}(n=8)$. The mean mechanical curve could be divided in two phases (Fig. 5B2). The slope of the curve regularly increased in the first phase from $2 \mathrm{~N} / \mathrm{cm}^{2}$ up to the maximum (16 $\mathrm{N} / \mathrm{cm}^{2}$ ). Beyond this point, the slope of the curve decreased and became negative. This curve is noticeably different from the PBe mechanical curve obtained in a previous work. In the lowpressure range, the PBil curve increases more than the PBe curve. After $16 \mathrm{~N} / \mathrm{cm}^{2}$, the PBil curve decreases, whereas the PBe curve is still increasing (see Discussion).

\section{Responses to electrical stimulation of PBil nociceptive neurons}

All nociceptive neurons tested responded to suprathreshold transcutaneous electrical stimulation applied to the receptive field. As in the illustrated case, the repeated electrical stimulation of very high intensity $(30 \mathrm{~mA})$ induced generally a progressive increase of firing in neurons that did not discharged initially (Fig. $6 A, B)$. A short silent period after the electrical stimuli and during 100-300 msec was nonetheless often observed (Fig. 6A2). Moreover, most of the neurons excited by electrical stimuli exhibited after the end of a natural noxious stimulus a strong and lasting afterdischarge that stopped, by its own, after 1 or several minutes (Fig. 6C).

\section{Effect of morphine on PBil nociceptive neurons}

The effects of intravenous injection of morphine $(3 \mathrm{mg} / \mathrm{kg})$ were tested on the response to noxious heat $\left(48^{\circ} \mathrm{C}\right)$ applied in the PRF. Morphine had clear depressive effects shown in an individual example in Figure $7 A$. The effect of morphine on ongoing activity was not noticeable because it was often very low or absent. On the other hand, in all cases, the injection of naloxone induced a marked increase of the ongoing activity, suggesting indirectly that the spontaneous activity could be decreased by morphine. The mean histogram (Fig. 7B) summarizes the individual data. Before the morphine injection, the mean frequency of the control response to $48^{\circ} \mathrm{C}$ was $22 \pm 8 \mathrm{~Hz}(n=5)$. Five and then $10 \mathrm{~min}$ after $3 \mathrm{mg} / \mathrm{kg}$ of intravenous morphine, the responses were markedly and significantly $(p<0.001)$ reduced to $23 \pm 6 \%$ and then to $31 \pm 7 \%$ of their initial value, respectively. After naloxone, the responses recovered to $90 \pm 15 \%$ of the control value.

\section{DISCUSSION}

Here we showed that most of PBil-intralaminar neurons convey and encode cutaneous nociceptive information to the intralaminar thalamus. The results of the antidromic stimulation further support anatomical data demonstrating that the PBil projects precisely to the intralaminar thalamus (primarily to the $\mathrm{PC}$ nucleus as shown in Fig. $1 A^{\prime}$ and to a lesser extent to the parafascicular and centromedial nuclei) (Fulwiler and Saper, 1984; Hermanson and Blomqvist, 1997b; Bester et al., 1999). 


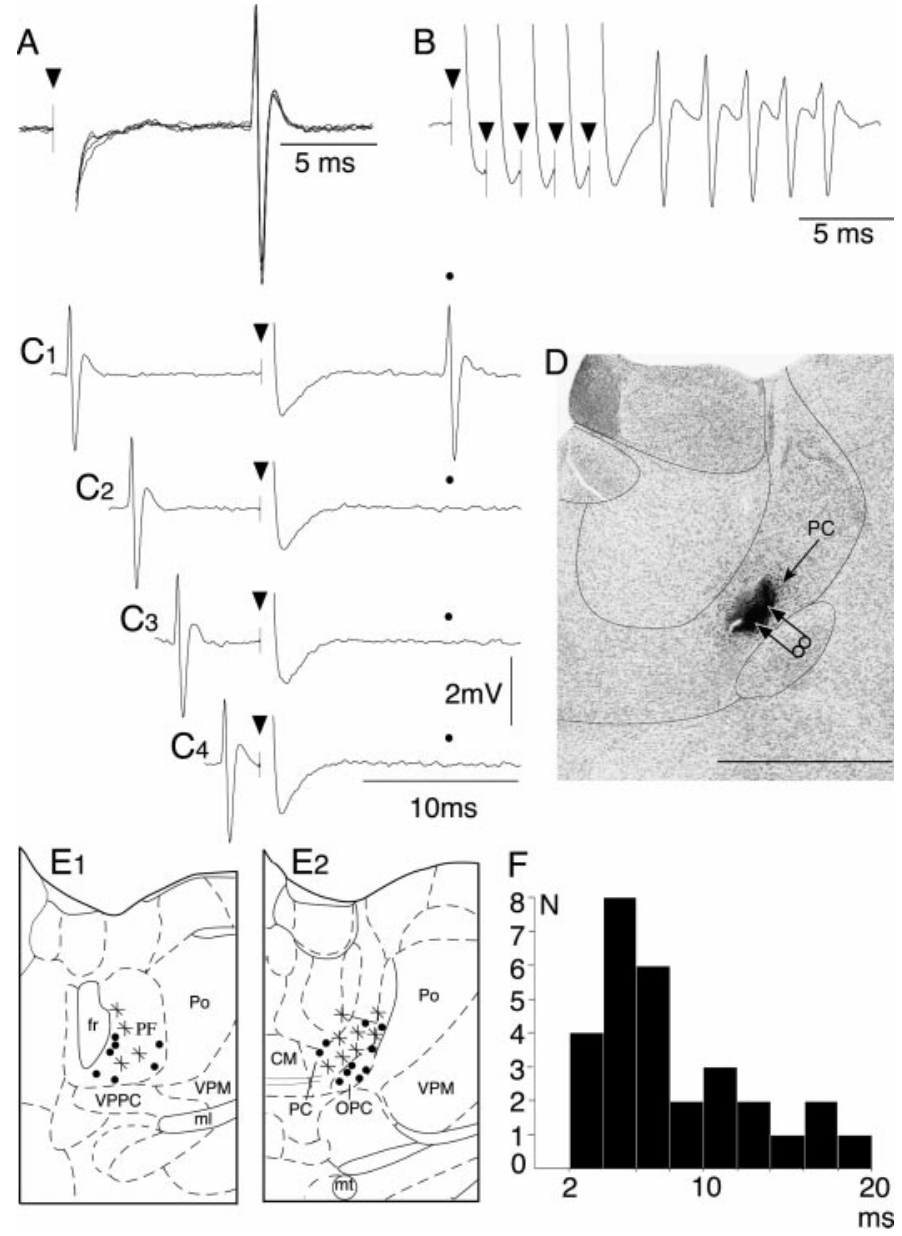

Figure 3. Antidromic activation of one parabrachiothalamic neuron recorded in the PBil. $A$, Superimposition of five antidromic spikes; note the perfect stability of the latency. $B$, High-frequency stimulation (5 pulses, $600 \mathrm{~Hz}$ ); note the capacity of the antidromic response to follow highfrequency stimulation. $C$, Collision test. Filled circle shows the expected location of the antidromic spike, and black triangle indicates the antidromic shock. $C 1$, The orthodromic spike fired before the $2 t+r$ collision period, and the antidromic spike occurred with $11 \mathrm{msec}$ latency. $C 2-C 4$, The orthodromic spike fired within the $2 t+r$ collision period, and the antidromic spike did not occur. $D$, Microphotograph of the corresponding Prussian blue point in the paracentral nucleus. E1, E2, Antidromic activation sites with thresholds $<200 \mu \mathrm{A}$ (asterisks) and $>200 \mu \mathrm{A}$ (black dots). $F$, Distribution histogram of the antidromic latencies. Scale bar (in $D), 1 \mathrm{~mm}$. $C M$, Central medial thalamic nucleus; $f r$, fasciculus retroflexus; $m l$, medial lemniscus; $O P C$, oval paracentral thalamic nucleus; $P f$, parafascicula thalamic nucleus; $P o$, posterior thalamic nuclear group; $V P M$, ventral posteromedial thalamic nucleus; $V P P C$, ventral posterior parvicellular thalamic nucleus.

\section{Nociceptive processing in the spino-PBil-PC pathway}

PBil-intralaminar neurons convey cutaneous nociceptive information that arises in large cutaneous receptive fields. They display long afterdischarges after intense and moderate nociceptive stimuli and never respond to clearly innocuous stimuli. The mean thermal $44.8 \pm 0.6^{\circ} \mathrm{C}(n=15)$ and mechanical $8 \pm 2.8 \mathrm{~N} / \mathrm{cm}^{2}(n=$ 8 ) thresholds are close to human pain thresholds $\left(\sim 45^{\circ} \mathrm{C}\right.$ and $\sim 7$ $\mathrm{N} / \mathrm{cm}^{2}$ ) (Hardy et al., 1967), but the encoding properties were limited to a narrow range of $\sim 44-48^{\circ} \mathrm{C}$ for thermal and $4-16$ $\mathrm{N} / \mathrm{cm}^{2}$ for mechanical stimuli. Furthermore, the response of PBil-PC neurons to noxious stimuli is clearly depressed by intravenous morphine $(3 \mathrm{mg} / \mathrm{kg})$. Based on these findings, we suggest

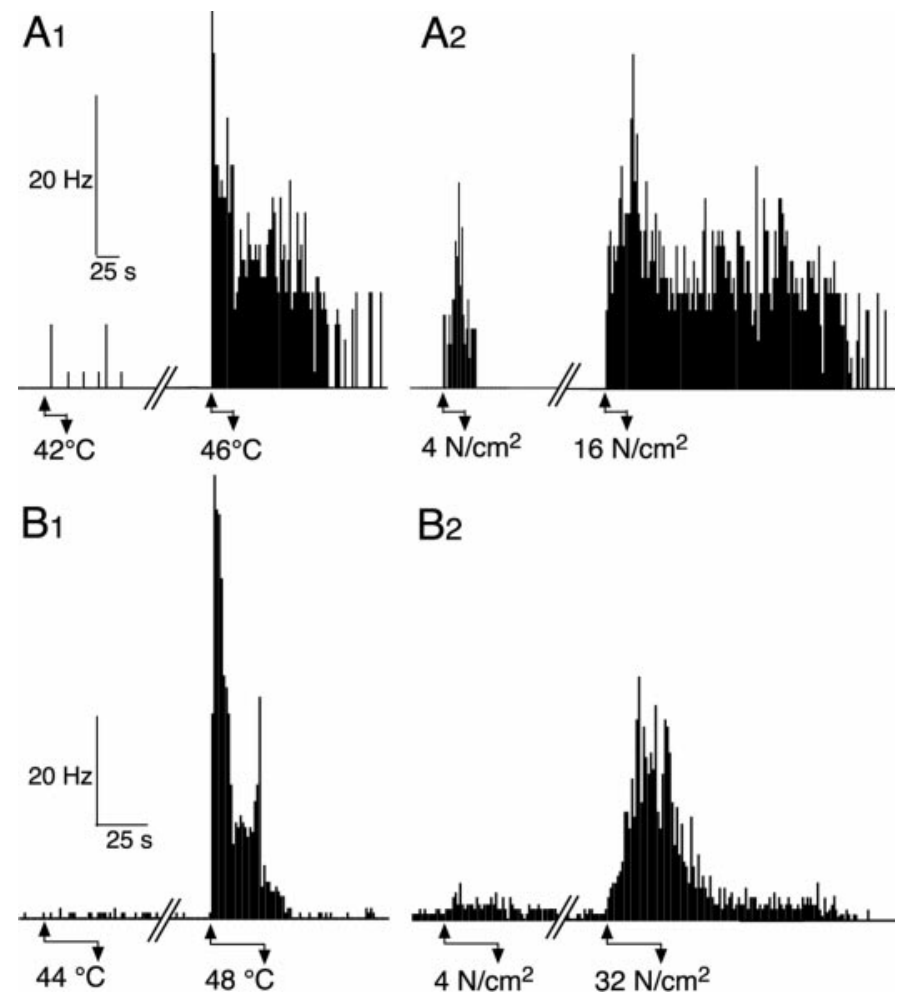

Figure 4. Responses of two PBil-PC neurons (one in $A$, the other in $B$ ) to innocuous (near the pain threshold) and noxious stimuli. Thermal $(A 1$, $B 1)$ and mechanical $(A 2, B 2)$ stimuli were applied for $24 \mathrm{sec}$ between the two arrows. Note that, in each case, the weak response to innocuous stimuli and the heavy and tonic response to noxious stimuli was followed by marked $(A)$ and moderate $(B)$ afterdischarges.

that PBil-PC neurons are involved in the processing of nociceptive information.

It must be borne in mind that the PBil nucleus is anatomically distinct from another parabrachial area, the $\mathrm{PBe}$, which was involved previously in nociceptive processing (Bernard and Besson, 1990; Bester et al., 1995) and which includes the lateral crescent, the external lateral, the dorsal lateral, the superior lateral, and the external medial parabrachial nuclei [Fulwiler and Saper, 1984, their Figs. 1, 2; Bester et al., 1997, their Fig. 1]. The PBil receives its nociceptive inputs from the spinal laminas V/VI and projects only to the intralaminar thalamic nuclei (see references in introductory remarks), whereas the $\mathrm{PBe}$ receives its inputs from the spinal lamina I (Cechetto et al., 1985; Bernard et al., 1995; Feil and Herbert, 1995; Craig and Dostrovsky, 1999 and references therein) and projects primarily to the amygdala and the hypothalamus (Saper and Loewy, 1980; Fulwiler and Saper, 1984; Bernard et al., 1993; Bester et al., 1997). Importantly, the nociceptive properties of the PBil nociceptive neurons are noticeably different from those of $\mathrm{PBe}$ nociceptive-specific neurons: the PBil neurons encode noxious stimuli in a narrower range (close to the nociceptive threshold) (Fig. 5) and have a tendency to be more sensitive to mechanical stimuli around the nociceptive threshold than the PBe neurons. The afterdischarges of PBil neurons were much more marked than those of PBe neurons.

The afterdischarge fitted well with the marked windup observed in PBil neurons when using electrical stimulation: the absence of response to the firsts electrical shocks followed by a progressive increase of firing that persists a long time after the end of the stimulation period. This indicates that PBil neurons 

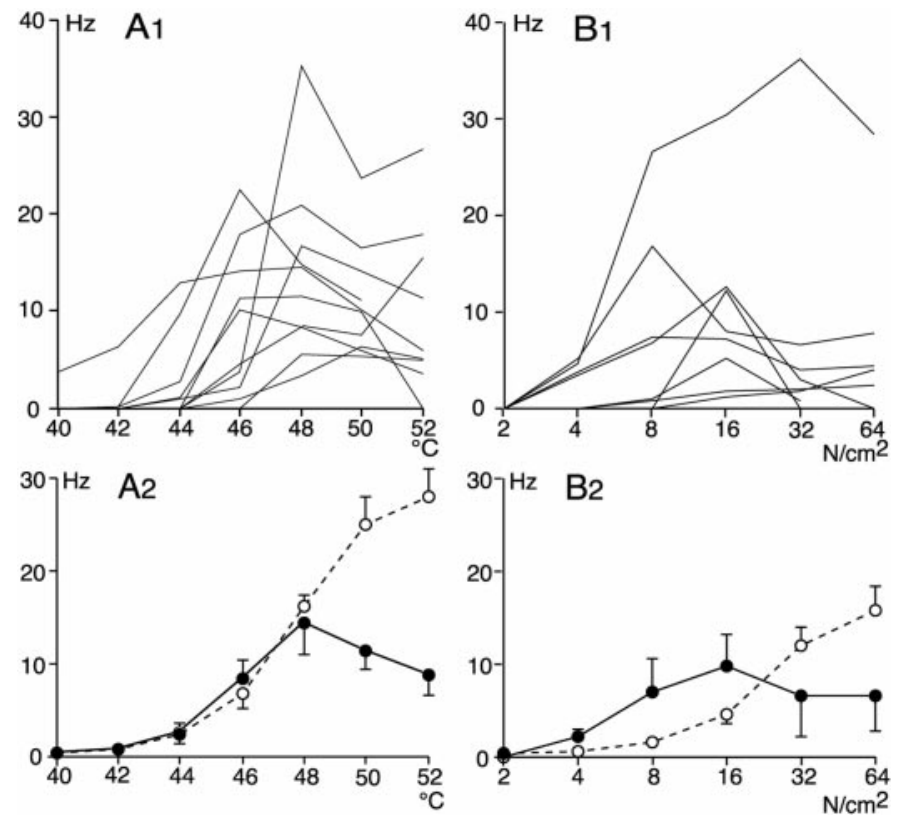

Figure 5. Stimulus-response curves of PBil-PC neurons. A1, Responses of individual neurons to graded thermal stimuli. A2, Mean stimulusresponse curve to graded thermal stimuli (solid line). B1, Response of individual neurons to graded mechanical stimuli. B2, Mean stimulusresponse curve to graded mechanical stimuli (solid line). In both $A 2$ and $B 2$, broken line illustrates, for comparison, the curves obtained in a previous study (Matsumoto et al., 1996) from external parabrachial area. Ordinate, Mean frequency of response; abscissa, stimulus temperature or pressure. Note that the pain thresholds can be estimated at $\sim 45^{\circ} \mathrm{C}$ and between 4 and $8 \mathrm{~N} / \mathrm{cm}^{2}$.

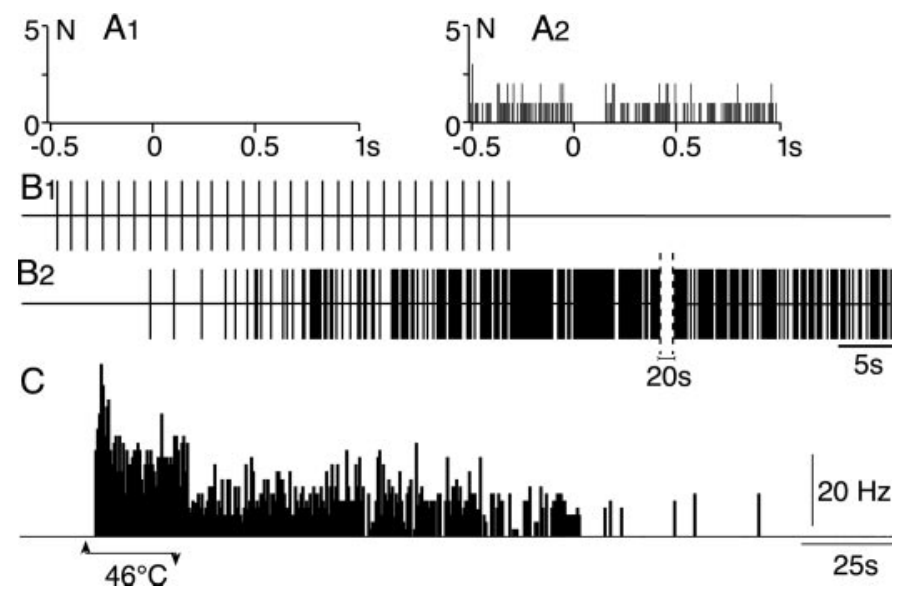

Figure 6. Response of one nociceptive PBil-PC neuron to transcutaneous electrical stimulation ( $30 \mathrm{~mA}, 2 \mathrm{msec}$ duration). A1, PSTH made without stimulation. $A 2$, PSTH made from responses to repetitive electrical stimulation $(0.66 \mathrm{~Hz}, 30$ trials) applied in the preferential receptive field. B1, Electrical stimulation $(0.66 \mathrm{~Hz}, 30$ trials; each line is one shock). $B 2$, Continuous response of the neuron to transcutaneous electrical stimulation (synchronous to $B 1$ ). $C$, Response of the same neuron to noxious thermal stimulus $\left(46^{\circ} \mathrm{C}\right)$ applied for $24 \mathrm{sec}$ between the two arrows.

could either respond adequately to prolonged noxious stimulus and/or signal pain after the interruption of the nociceptive stimulation. Another important feature of PBil neurons is that their highest response arises to a specific nociceptive strength $\left(48^{\circ} \mathrm{C}\right.$ and $16 \mathrm{~N} / \mathrm{cm}^{2}$ ), which corresponds, at least for thermal modality (Neisser, 1959), to the threshold of unbearable pain. Above and
A
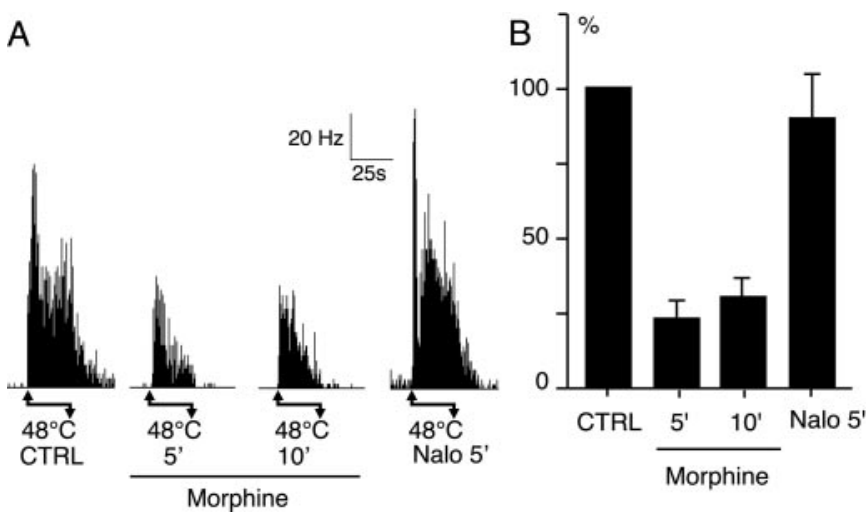

Figure 7. Depressive effect of intravenous morphine $(3 \mathrm{mg} / \mathrm{kg})$ on the effect of PBil neurons. $A$, Effect in one individual case. Noxious stimuli $\left(48^{\circ} \mathrm{C}\right)$ was applied for $24 \mathrm{sec}$ between the arrows. 5', 10', Nalo 5', Responses 5 and $10 \mathrm{~min}$ after morphine and $5 \mathrm{~min}$ after naloxone administration. $B$, Mean effect of morphine in percent of the control response. CTRL, Mean control response of PBil neurons $(n=5) .5^{\prime}, 10^{\prime}$, Nalo $5^{\prime}$, Mean response of the same neurons 5 and $10 \mathrm{~min}$ after morphine and 5 min after naloxone administration.

below this point, the firing was clearly less intense. Thus, it is tempting to speculate that PBil neurons would be tuned to indicate the threshold of unbearable pain. Beyond the tuned nociceptive intensity, PBil firing within narrow ranges would avoid saturating the corresponding thalamo-cortical network.

The particular responsiveness of PBil neurons cannot be totally explained by the nociceptive input they receive from the medial and the lateral reticular portion of laminas V/VI (Kitamura et al., 1993; Bernard et al., 1995; Feil and Herbert, 1995) because most neurons recorded in laminas V/VI are nociceptive of wide dynamic range (Menétrey et al., 1977, 1979, 1984; Dado et al., 1994), whereas most PBil neurons are nociceptive with a narrower dynamic range. There are two possible explanations.

(1) The spino-PBil neurons, which have not been studied physiologically, may be either mostly nociceptive-specific (such neurons were also observed in laminas V/VI) or have properties closer to those of PBil neurons.

(2) The dynamic of response observed in the present study could result from specific filtering gains by local modulation at the PBil level. The properties of the local network could be linked, at least in part, to a particular synaptic transmission in the PBil: it is the only parabrachial subnucleus containing AMPA glutamate receptors of the GluRD/4 type (Chamberlin and Saper, 1995; Guthmann and Herbert, 1999), the highest density fitting especially well with the dorsal location of spinal laminas V/VI input in the dorsal aspect of the PBil (Fig. $\left.1 B^{\prime}\right)$. This second explanation fits rather well with the hypothesis of a specific PBil tuning. In the framework of this hypothesis, the windup observed at the PBil level could be related to the windup of the spinal wide dynamic range neurons plus a PBil synaptic filter.

No previous electrophysiological study has focused on the caudal PC nucleus, the main target of the PBil. However, recordings in and around the intralaminar nuclei, including the PC, showed that a number of neurons responded to noxious stimuli from a very large receptive field (Dong et al., 1978; Dostrovsky and Guilbaud, 1990). Furthermore, Rinaldi et al. (1991) observed spontaneous hyperactivity in intralaminar thalamic nuclei in human suffering of chronic pain associated with deafferentation. All of these data support the involvement of the spino-PBil-PC pathway in nociceptive processing. 


\section{Functional considerations}

The projection targets of PC thalamic nuclei are the striatum and the cortex (Berendse and Groenewegen, 1991). The stimulation of intralaminar nuclei induces cortical recruiting responses (Morison and Dempsey, 1942; Jasper, 1960) that are usually accompanied by an increase of the cortical responsiveness to peripheral stimuli ( $\mathrm{Li}$ et al., 1955). Because the PBil-PC neurons are excited just above the nociceptive threshold with a longlasting afterdischarge, they could increase durably, via a lasting excitation of PC neurons, the responsiveness of the corresponding striatal-cortical compartment as soon as the pain threshold is reached.

The PC nucleus has been involved in alertness and high vigilance states (Glenn and Steriade, 1982; Kinomura et al., 1996). The cortical target of the PC, namely the lateral orbital, the lateral agranular, and the dorsomedial prefrontal areas (Berendse and Groenewegen, 1991), seems to play an important role in high cognitive functions (Aggleton et al., 1995), as well as in modulation of aggressive behavior, emotional states, and associated autonomic regulations (Frysztak and Neafsey, 1994; Giancola, 1995; Morgan and LeDoux, 1995). Consequently, the spinoPBil-PC-prefrontal nociceptive pathway could be involved, through an arousal of prefrontal (striatal) compartments, in cognitive, attentional, and emotional strategies to cope with noxious stimulation.

Although the switch from the rat to the human remains hazardous, it seems reasonable to hypothesize that the spino-PBilPC-prefrontal nociceptive pathway exists and could contribute to emotional aspects of pain in human. Surgery to relieve intractable pain may enlighten us about the role of this system. Freeman and Watts (1948) observed that a prefrontal lobotomy makes patients tolerant to their chronic unbearable pain. These authors report that "Following operation he continued to have pain and to react to them as before, but the haunting fear of them disappeared and thus changed his entire outlook on life" and more generally "it does not relieve the pain but rather the disabling reaction to pain, the fear of pain." Thus, it is tempting to hypothesize that the spino-PBil-PC-prefrontal nociceptive pathway could contribute to trigger among the most aversive emotional aspects of pain (a dreadful feeling and the haunting fear of pain) that makes the life of chronic painful patient so unbearable.

The existence of a pain pathway directed to the prefrontal cortex fits well with the cognitive-emotional framework of Damasio's group (Bechara et al., 2000). Indeed the finding of the spino-PBil-PC-prefrontal nociceptive pathway supports the involvement of the prefrontal cortex in pain processing. Thus, according to Damasio's theory, it becomes easier to believe that the prefrontal cortex might also generate "pseudopainful sensation," associating them to potentially dangerous ways and/or bad decisions in the life of an individual.

\section{REFERENCES}

Aggleton JP, Neave N, Nagle S, Sahgal A (1995) A comparison of the effects of medial prefrontal, cingulate cortex, and cingulum bundle lesions on tests of spatial memory: evidence of a double dissociation between frontal and cingulum bundle contributions. J Neurosci 15:7270-7281.

Bechara A, Damasio H, Damasio AR (2000) Emotion, decision making and the orbitofrontal cortex. Cereb Cortex 10:295-307.

Benoist JM, Kayser V, Gautron M, Guilbaud G (1984) Letter to the editor. Pain 18:410-411.

Berendse HW, Groenewegen HJ (1991) Restricted cortical termination fields of the midline and intralaminar thalamic nuclei in the rat. Neuroscience 42:73-102.

Bernard JF, Besson JM (1990) The spino(trigemino)pontoamygdaloid pathway: electrophysiologica 1 evidence for an involvement in pain processes. J Neurophysiol 63:473-490.

Bernard JF, Alden M, Besson JM (1993) The organization of the efferent projections from the pontine parabrachial area to the amygdaloid complex: a Phaseolus vulgaris leucoagglutinin (PHA-L) study in the rat. J Comp Neurol 329:201-229.

Bernard JF, Dallel, R, Raboisson, P, Villanueva, L, Le Bars D (1995) Organization of the efferent projections from the spinal cervical enlargement to the parabrachial area and periaqueductal gray: a PHA-L study in the rat. J Comp Neurol 353:480-505.

Besson JM, Chaouch A (1987) Peripheral and spinal mechanisms of nociception. Physiol Rev 67:67-185.

Bester H, Menendez L, Besson JM, Bernard JF (1995) The spino(trigemino)parabrachiohypothalamic pathway: electrophysiological evidence for an involvement in pain processes. J Neurophysiol 73:568-585.

Bester H, Besson JM, Bernard JF (1997) Organisation of the efferent projections from the parabrachial area to the hypothalamus: a PHA-L study in the rat. J Comp Neurol 383:245-281.

Bester H, Bourgeais L, Villanueva L, Besson JM, Bernard JF (1999) Differential projections to the intralaminar, gustatory thalamus from the parabrachial area: a PHA-L study in the rat. J Comp Neurol 405:421-449.

Bowsher D (1976) Role of the reticular formation in response to noxious stimulation. Pain 2:361-378.

Casey KL (1971) Response of bulboreticular units to somatic stimuli eliciting escape behaviour in the cat. Int J Neurosci 2:15-28.

Cechetto DF, Standaert DG, Saper CB (1985) Spinal and trigeminal dorsal horn projections to the parabrachial nucleus in the rat. J Comp Neurol 240:153-160.

Chamberlin NL, Saper CB (1995) Differential distribution of AMPAselective glutamate receptor subunits in the parabrachial nucleus of the rat. Neuroscience 68:435-443.

Craig AD, Dostrovsky JO (1999) Medulla to thalamus. In: Textbook of pain, Ed 4 (Wall PD, Melzack R, eds), pp 183-214. London: Churchill Livingstone.

Dado RJ, Katter JT, Giesler GJ (1994) Spinothalamic and spinohypothalamic tract neurons in the cervical enlargement of rats. II. responses to innocuous and noxious mechanical and thermal stimuli. J Neurophysiol 71:981-1002.

Dong WK, Ryu H, Wagman IH (1978) Nociceptive responses of neurons in medial thalamus and their relationship to spinothalamic pathways. J Neurophysiol 41:1592-1613.

Dostrovsky JO, Guilbaud G (1990) Nociceptive responses in medial thalamus of the normal and arthritic rat. Pain 40:93-104.

Feil K, Herbert H (1995) Topographic organization of spinal and trigeminal somatosensory pathways to the rat parabrachial and KollikerFuse nuclei. J Comp Neurol 353:506-528.

Freeman W, Watts JW (1948) Pain mechanisms and the frontal lobes: a study of prefrontal lobotomy for intractable pain. Ann Int Med 28:747-754.

Frysztak RJ, Neafsey EJ (1994) The effect of medial frontal cortex lesions on cardiovascular conditioned emotional responses in the rat. Brain Res 643:181-193.

Fulwiler CE, Saper CB (1984) Subnuclear organization of the efferent connections of the parabrachial nucleus in the rat. Brain Res 319:229-259.

Giancola PR (1995) Evidence for dorsolateral and orbital prefrontal cortical involvement in the expression of aggressive behavior. Aggress Behav 21:431-450.

Glenn LL, Steriade M (1982) Discharge rate and excitability of cortically projecting intralaminar thalamic neurons during waking and sleep states. J Neurosci 2:1387-1404.

Guthmann A, Herbert H (1999) In situ hybridization analysis of flip/flop splice variants of AMPA-type glutamate receptor subunits in the rat parabrachial and Kolliker-Fuse nuclei. Mol Brain Res 74:145-157.

Hardy JD, Wolff HG, Goodell H (1967) Pain sensations and reactions. New York: Hafner.

Hermanson O, Blomqvist A (1997a) Differential expression of the AP$1 /$ CRE-binding proteins Fos and CREB in preproenkephalin mRNAexpressing neurons of the rat parabrachial nucleus after nociceptive stimulation. Mol Brain Res 51:188-196.

Hermanson O, Blomqvist A (1997b) Preproenkephalin messenger RNAexpressing neurons in the rat parabrachial nucleus: subnuclear organization and projections to the intralaminar thalamus. Neuroscience 81:803-812.

Jasper HH (1960) Unspecific thalamocortical relations. In: Handbook of physiology, Sec 1, Vol 2 (Field J, Magoun HW, Hall VE, eds), pp 1307-1321. Washington, DC: American Physiological Society.

Kinomura,S, Larsson, J, Gulyas, B, Roland PE (1996) Activation by attention of the human reticular formation and thalamic intralaminar nuclei. Science 271:512-515.

Kitamura, T, Yamada J, Sato, H, Yamashita K (1993) Cells of origin of the spinoparabrachial fibers in the rat: a study with fast blue and WGA-HRP. J Comp Neurol 328:449-461.

Li CL, Cullen C, Jasper HH (1955) Laminar microelectrode analysis of 
cortical unspecific recruiting responses and spontaneous rhythms. J Neurophysiol 19:131-143.

Matsumoto N, Bester H, Menendez L, Besson JM, Bernard JF (1996) Changes in the responsiveness of parabrachial neurons in the arthritic rat: an electrophysiological study. J Neurophysiol 76:4113-4126.

Menétrey D, Giesler GJ, Besson JM (1977) An analysis of response properties of spinal cord dorsal horn neurones to nonnoxious and noxious stimuli in the spinal rat. Exp Brain Res 27:15-33.

Menétrey D, Chaouch A, Besson JM (1979) Responses of spinal cord dorsal horn neurones to non-noxious and noxious cutaneous temperature changes in the spinal rat. Pain 6:265-282.

Menétrey D, De Pommery J, Besson JM (1984) Electrophysiological characteristics of lumbar spinal cord neurons backfired from lateral reticular nucleus in the rat. J Neurophysiol 52:595-611.

Monconduit L, Bourgeais L, Bernard JF, Le Bars D, Villanueva L (1999) Ventromedial thalamic neurons convey nociceptive signals from the whole body surface to the dorsolateral neocortex. J Neurosci 19:9063-9072.

Morgan MA, LeDoux JE (1995) Differential contribution of dorsal and ventral medial prefrontal cortex to the acquisition and extinction of conditioned fear in rats. Behav Neurosci 109:681-688.

Morison RS, Dempsey EW (1942) A study of thalamo-cortical relations. Am J Physiol 135:281-292.
Neisser U (1959) Temperature thresholds for cutaneous pain. J Appl Physiol 14:368-372.

Paxinos G, Watson C (1998) The rat brain in stereotaxic coordinates. Ed 4. Sydney: Academic.

Rainville P, Duncan GH, Price DD, Carrier B, Bushnell MC (1997) Pain affect encoded in human anterior cingulate but not somatosensory cortex. Science 277:968-971.

Rinaldi PC, Young RF, Albe-Fessard D, Chodakiewitz J (1991) Spontaneous neuronal hyperactivity in the medial and intralaminar thalamic nuclei of patients with deafferentation pain. J Neurosurg 74:415-421.

Saper CB, Loewy AD (1980) Efferent connections of the parabrachial nucleus in the rat. Brain Res 197:291-317.

Villanueva L, Bouhassira D, Le Bars D (1996) The medullary subnucleus reticularis dorsalis (SRD) as a key link in both the transmission and modulation of pain signals. Pain 67:231-240.

Villanueva L, Desbois C, Le Bars D, Bernard JF (1998) Organization of diencephalic projections from the medullary subnucleus reticularis dorsalis and the adjacent cuneate nucleus: a retrograde and anterograde tracer study in the rat. J Comp Neurol 390:133-160.

Willis WD, Westlund KN, Carlton SM (1995) Pain. In: The rat nervous system, Ed 2 (Paxinos G, ed), pp 725-750. Sydney: Academic. 